\title{
Identification of dynamic properties of radial air-foil bearings
}

\author{
V. Arora · P. J. M. van der Hoogt • \\ R. G. K. M. Aarts $\cdot$ A. de Boer
}

Received: 26 April 2010/ Accepted: 27 August 2010/Published online: 21 October 2010

(C) The Author(s) 2010. This article is published with open access at Springerlink.com

\begin{abstract}
Air-foil bearings (AFBs) are self acting hydrodynamic bearings made from sheet metal foils comprised of at least two layers. The innermost "top foil" layer traps a gas pressure film that supports a load while the layer or layers underneath provide an elastic foundation. Air-foil bearings are currently used in many commercial applications, both terrestrial and aerospace. Air-foil bearings provide a means to eliminate the oil system leading to reduce weight and enhanced temperature capability. Regardless of the application of the air-foil bearings, the identification of the dynamic characteristics is important for successful design practice. In the present work, stiffness and damping of radial air-foil bearings are indentified in the light of experimental results. Due to the initial high torque requirement of the air-foil bearing, the experimental setup using single air-foil bearing is proposed instead of standard two-foil bearing setups. Experiments are carried out at maximum speed of $60,000 \mathrm{rpm}$. Sub-structuring approach is used for identification of stiffness and damping properties of the air-foil bearings. The results have shown that the developed experimental procedure is
\end{abstract}

V. Arora $(\bowtie)$ · P. J. M. van der Hoogt · A. de Boer Structural Dynamics and Acoustics, University of Twente, P.O. Box 217, 7500 AE Enschede, The Netherlands e-mail: v.arora@utwente.nl

R. G. K. M. Aarts

Mechanical Automation, University of Twente, P.O. Box 217, 7500 AE Enschede, The Netherlands able to indentify the stiffness and damping properties of radial air-foil bearings accurately.

Keywords Radial air-foil bearings - Stiffness and damping identification $\cdot$ Sub-structuring $\cdot$ High speed

\section{Introduction}

Air-foil bearings (AFBs) are currently used in many commercial applications, both terrestrial and in aerospace. Air-foil bearings provide a means to eliminate the oil system leading to reduce weight and enhanced temperature capability. AFBs are complaint-surface use ambient air as the lubricant fluid. A hydrodynamic pressure builds up within the small gap or film between rotating shaft and the top foil. Figure 1 shows the configuration of a "first generation" bump type AFB. The AFB consists of a thin (top) foil and a series of corrugated bump strip supports. The leading edge of the top foil is free, and the foil trailing edge is welded to the bearing housing. Beneath the top foil, a bump structure is laid on the inner surface of the bearing. The top foil of the smooth surface is supported by a series of bumps acting as springs, thus making the bearing complaint. The bump foil layer gives the bearing flexibility that allows it to tolerate significant amounts of misalignment and distortion that would otherwise cause a rigid (Oil lubricated) bearing to fail. In addition, micro-sliding between top foil and bump foil generates coulomb damping which can increase the 


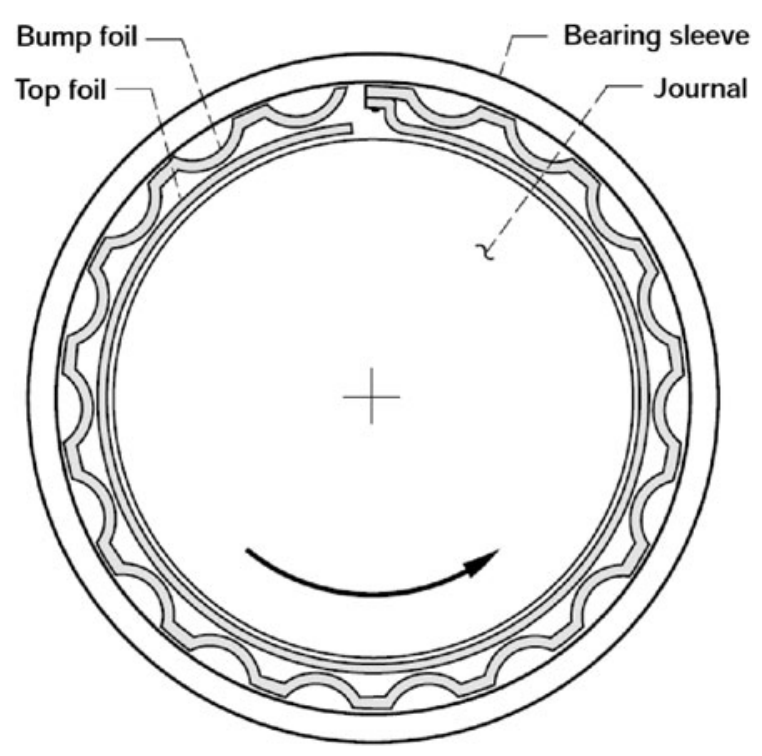

Fig. 1 Compliant air-foil journal bearing

dynamic stability of the rotor-bearing system. During normal operation of the foil bearing supported machine, the rotation of the rotor generates a pressurized gas film that pushes the top foil out radially and separate the top foil from the surface of the rotating shaft. The pressure in the air film is proportional to the relative surface velocity between the rotor and top foil. Thus, faster the rotor rotates, the higher the pressure, and the more is the load the bearing can support. When the rotor first begins to rotate, the top foil and the rotor surface are in contact until the speed increases to a point where the pressure in the air film is sufficient to push the top foil away from the rotor and support its weight. This threshold speed is generally referred as liftoff speed. Likewise, when the rotor slows down to a point where the speed is insufficient to support the rotor weight, the top foil and rotor again come in contact.

The dynamic behavior of a rotating system is significantly influenced by the structural (stiffness and damping) characteristics of the bearings. The exact values of the stiffness and damping coefficients of air-foil bearings are difficult to predict. The identification of structural characteristics of air-foil bearings can be classified broadly into two categories:

1. Mathematical route

2. Experimental route

The geometric configuration of air-foil bearing is very complicated and numerical calculations of various air-foil bearing characteristics are difficult and also they do not predict accurately the dynamics of complete support-rotor-bearing system. The mathematical route uses empirical values, mainly film thickness and dry friction coefficients, to develop mathematical models. The mathematical models of air-foil bearings developed using empirical values do not predict the behavior of complete rotor-bearing system at different rotating speeds. The determination of stiffness and damping in air-foil bearing is a difficult task and optimization techniques provide an alternative technique for identification. In the optimization technique, finite element model is corrected in the light of experimental data. Predictions capabilities of the rotor-bearing systems can be improved significantly by identify the dynamic characteristics of the air-foil bearing using optimization techniques. Hence, in this work, firstly a detail is given regarding the mathematical techniques, which uses empirical values, and then emphasis will be on the optimization techniques.

$\mathrm{Ku}$ and Heshmat (1993) presented an analytical procedure to identify the dynamic stiffness and the equivalent viscous damping of air-foil Bearings (AFBs). A simple analytical model assembles individual bump stiffnesses and renders predictions for the AFB structural stiffness as a function of the bump geometry and material, dry-friction coefficient, load orientation, clearance and preload. The dry-friction coefficient and clearance values are obtained from the experiment. Ku (1993) described an experimental investigation to characterize the structural dynamic force coefficients of corrugated bumps used in foil bearings. Dynamic force perturbations are imposed to a six-bump strip under different test conditions and various bump geometrical configurations using dry friction coefficients ranging from 0.4 to 0.6 , depending on the surface coating. Heshmat and $\mathrm{Ku}$ (1994) developed an experimental procedure to identify the structural stiffness and equivalent viscous damping coefficient by exciting, with two electromagnetic shakers, a non-rotating shaft supported on AFBs. This procedure uses empirical values of clearance and dry friction for predicting stiffness and damping characteristics of air-foil bearing at different rotational speeds. An analytical models ( $\mathrm{Ku}$ and Heshmat 1994a, b), uses bumps curvature effect, force interaction between bumps, and the dry friction coefficient ranging from 0.4 to 0.6 for predicting stiffness and 
damping characteristics. Salehi et al. (2003) performed dynamic force tests on corrugated metal sheets (bump foil strips). Dynamic force excitations are exerted on the bump strip using an electromagnetic shaker at various load and frequency conditions. Equivalent viscous damping coefficients and dry friction forces are extracted from the resulting hysteresis loops (force versus displacement) for various test conditions. DellaCorte and Valco (2000) introduced a simple "rule of thumb" method to estimate the load capacity in foil gas journal bearings. The method relates the bearing load capacity to the bearing size and the speed through an empirically based load capacity coefficient. Rubio and San Andrés (2006) estimated the dry friction coefficients from shaker-exerted dynamic load tests. It can be observed from the above references that stiffness and damping characteristics are predicted by using mathematical model of the air-foil bearing and empirical values of clearance and dry friction coefficients. These empirical values used in the mathematical models do not predict the rotor-bearing systems completely at different rotating speeds. Predictions capabilities of the rotor-bearing systems can be improved significantly by identifying the dynamic characteristics of the system using optimization techniques. The optimization techniques, correct the finite element model in the light of experimental data. The state of the art of the optimization techniques for identification of structural characteristics are presented in the section below.

An important application of the optimization procedure in mechanical system is devoted to inverse problems. The determination of the structural properties of bearings is a difficult task and optimization techniques provide an alternative way for the identification of structural properties of bearings. Some researchers have focused on using an optimization scheme to correct the finite element model to determine the objective function that quantifies the difference between experimental data and analytical data (Arora et al. (2009a, b)). During the past decade, many research works have dealt with identification of structural characteristics of bearings and rotor-bearing systems using optimization techniques. These optimization techniques require correction of the finite element model of the rotating system in the light of experimental data. Lee and Hong (1998) proposed an identification scheme for estimation of structural characteristics of bearings from out of balance response. Chen and Lee (1995) proposed a new method of estimating coefficients of bearings. Edwards et al. (2002) identified the unbalance and support parameters of flexible rotor-bearings-foundation system from single rundown. Jiang and $\mathrm{Yu}$ (2000) studied the identification of dynamic characteristics of journal and axial bearings. Tiwari et al. (2002) identified speed-dependent bearing parameters using unbalance response measurement for multidegree-of freedom flexible rotor-bearing system. Kim et al. (2007) identify the bearing characteristics using genetic algorithm. The procedure can identify not only unknown bearing stiffness but also unbalance information of the disk.

The air-foil bearing requires a high initial torque. San Andrés and Kim (2008) developed an experimental setup, which uses two motors, one starting motor and one high speed motor. The starting motor assists to start up the rotor and operating is shifted to high speed motor after starting through a centrifugal clutch. (Kim and Park 2009; Isomura et al. 2005; Belforte et al. 2006) developed experimental setup using a high torque turbine for testing the airfoil bearings.

In this paper, an experimental setup is proposed which uses a single one air-foil bearing. The use of only one air-foil bearing will reduce the initial torque requirement as well as cost of an experimental setup significantly and also it will not affect the credibility of the experimental results. The identification algorithm, which uses the vibration data of the complete rotor system, for identifying structural characteristics of the air-foil bearings has also been developed. This identification technique also requires developing a sub-structuring procedure.

\section{Theory}

In this section, a structural characteristics identification procedure and algorithm is presented. The structural identification procedure is based on the sub-structuring technique. In the sub-structuring technique, each component is considered in isolation. The structural properties of the isolated structure are identified using experimental data. All the isolated components are subsequently assembled to make complete rotor-bearing-support system. The identification algorithm is then applied to complete system 
to identify the structural characteristics of air-foil bearings. The identification algorithm used in the present work, is an inverse eigensensitivity method. In this method, the unknown bearing stiffness value is determined by using eigenvalue sensitivity. So the identification consists of two steps: sub-structuring and an identification algorithm for identification of stiffness of air-foil bearing.

\subsection{Sub-structuring}

The schematic diagram of the rotor-bearing-support system is shown in the Fig. 2. It can be observed from the Fig. 2 that the rotor-bearing-support system consists of five components, namely the motor support, motor, rotor, axial air-foil bearing and axial bearing support. The structural characteristics of isolated individual components, except the radial air-foil bearing, is identified/corrected in light of experimental data as shown in Fig. 3. All the components are subsequently assembled to form the complete rotor-bearing-support system. The air-foil bearing characteristics are identified in the last step. The rotor-bearing-support system can be written in terms of dynamic stiffness matrices of its constituent components as:

$$
\begin{aligned}
& Z_{R} u_{R}=f_{R} \\
& Z_{B} u_{B}=f_{B} \\
& Z_{S} u_{S}=f_{S}
\end{aligned}
$$

where $Z$ is the subscript-dependent dynamic stiffness matrix of the local system component, $u$ is the subscript-dependent response vector and $\mathrm{f}$ is subscript dependent force. Subscripts R, B, S relate to rotor, bearings and supports respectively. The individual dynamic stiffness matrices of each component are:

$$
\begin{aligned}
& Z_{R}(\omega)=K_{R}-\omega^{2} M_{R}+j \omega C_{R} \\
& Z_{B}(\omega)=K_{B}+j \omega C_{B} \\
& Z_{S}(\omega)=K_{S}-\omega^{2} M_{S}+j \omega C_{S}
\end{aligned}
$$

where $\mathrm{K}, \mathrm{M}, \mathrm{C}$ are the subscript-dependent stiffness, mass and damping matrices. The equations presented in the sub-components of rotor-dynamic system are combined to form the whole system as:

$$
\left[\begin{array}{cc}
Z_{R}+Z_{B} & -Z_{B} \\
-Z_{B} & Z_{B}+Z_{S}
\end{array}\right]\left\{\begin{array}{l}
u_{R} \\
u_{S}
\end{array}\right\}=\left\{\begin{array}{l}
f \\
0
\end{array}\right\}
$$

It can be noticed from Eq. 7 that the rotor-bearingsupport system is portioned into rotor, bearing and support components to identify the dynamic characteristics of the rotor-bearing-support system. The goal
Fig. 2 Schematic diagram of rotor-bearing system

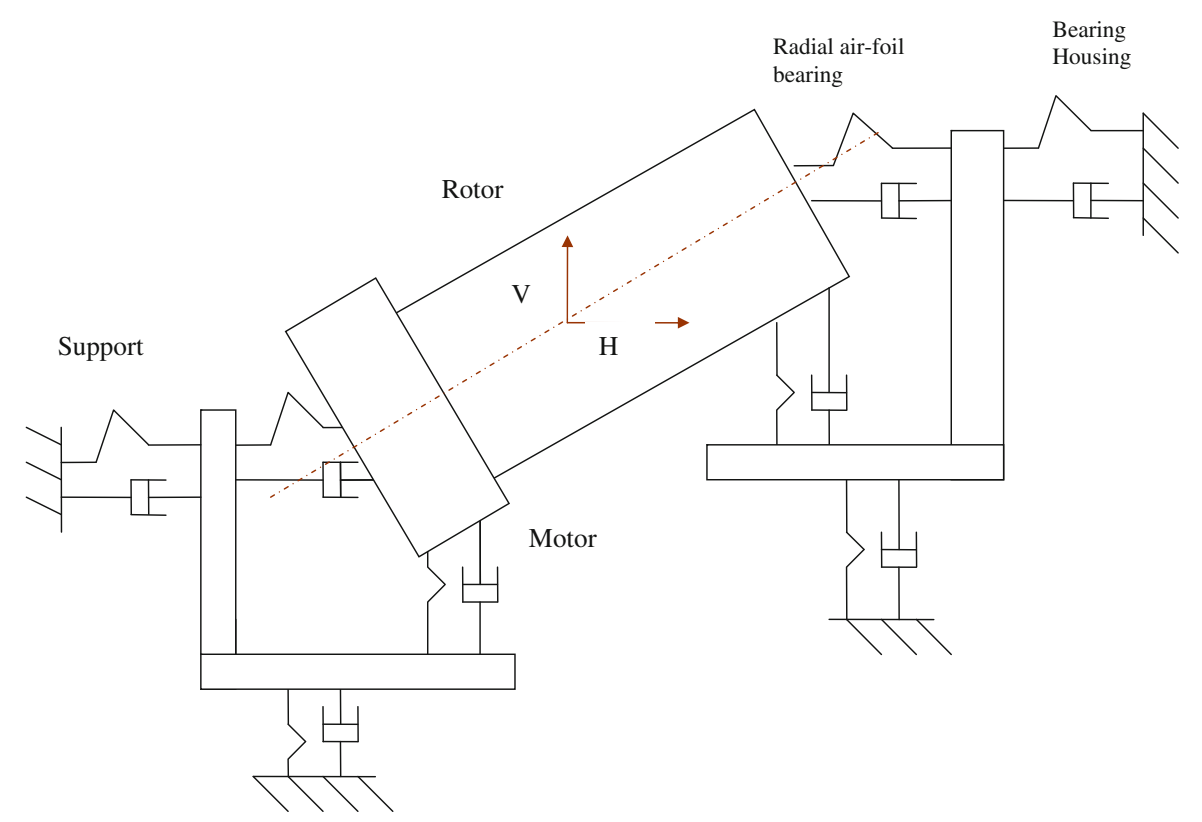


Fig. 3 Flow chart of proposed identification procedure for air-foil bearing

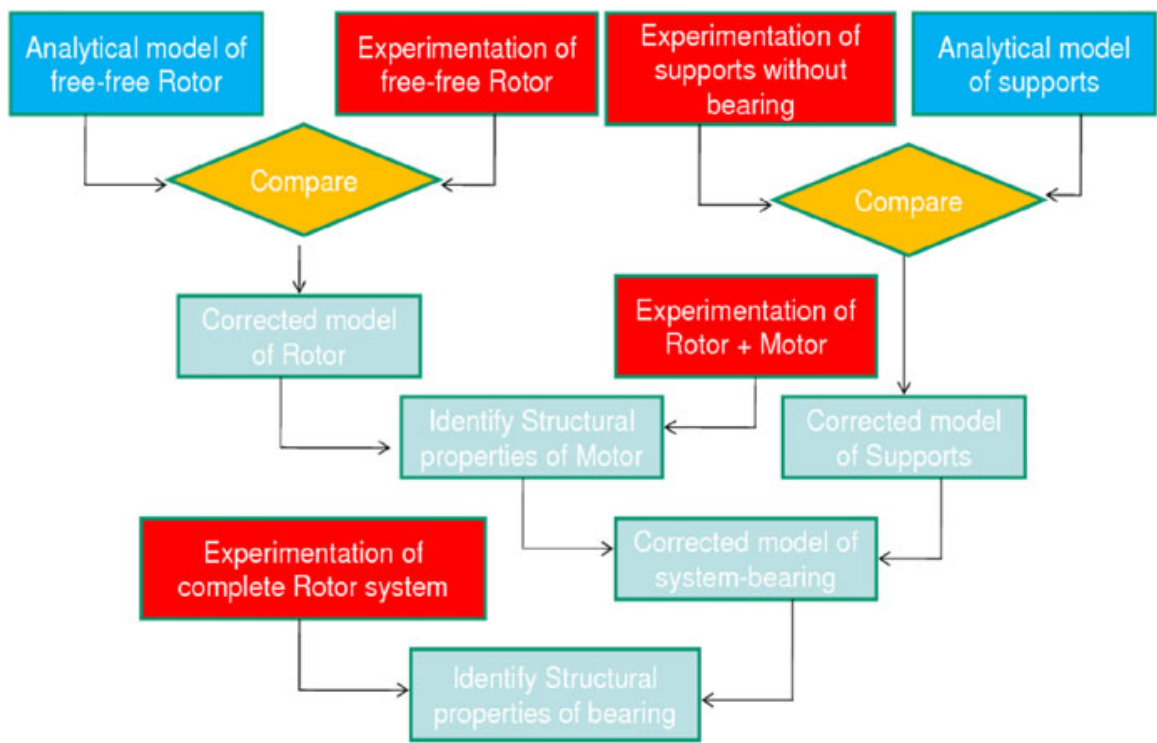

of partition is to use the eigendata of each component separately to identify the dynamic characteristics of each component.

\subsection{Identification algorithm}

The identification algorithm is based on the inverse eigensensitivity method (Modak et al. 2000). This method uses eigendata namely eigenvalues, eigenvectors and damping ratios, which are obtained by modal analysis of measured FRFs. The updating parameters corresponding to the finite element model are corrected to bring FE eigendata closer to that of experimentally derived ones. Most often updating equations is based on a linear approximation of the modal data that is generally a nonlinear function of the updating parameters. The linearization of $\mathrm{rth}$ eigenvalue $\lambda^{r}$ gives:

$\lambda_{X}^{r}=\lambda_{A}^{r}+\sum_{i=1}^{n u}\left(\frac{\partial \lambda_{A}^{r}}{\partial p_{i}} \Delta p_{i}\right)$

where subscripts $\mathrm{A}$ and $\mathrm{X}$ denote analytical and experimental respectively. $\mathrm{p}$ is the updating parameter and nu is number of updating parameters. Eigen sensitivities are represented by derivatives, can be calculated by from relationship given by Fox and Kapoor (1968) as: $\frac{\partial \lambda_{A}^{r}}{\partial p_{i}}=\{\phi\}_{A}^{r T}\left[\frac{\partial K}{\partial p_{i}}-\lambda_{A}^{r} \frac{\partial M}{\partial p_{i}}\right]\{\phi\}_{A}^{r}$

where $\{\phi\}_{A}^{r}$ is the rth mass-normalized eigenvector. Using Eqs. 9 and 8 can be written for the chosen $m$ number of modes. These equations together, after dividing and multiplying by $\mathrm{p}_{\mathrm{i}}$ and then writing $\mathrm{u}_{\mathrm{i}}$ in place of $\frac{\Delta p_{i}}{p_{i}}$ can be written in the following matrix form:

$\left[\begin{array}{cccc}p_{1} \cdot \frac{\partial \lambda_{A}^{1}}{\partial p_{1}} / \lambda_{A}^{1} & p_{2} \cdot \frac{\partial \lambda_{A}^{1}}{\partial p_{2}} / \lambda_{A}^{1} & \ldots & p_{n u} \cdot \frac{\partial \lambda_{A}^{1}}{\partial p_{n u}} / \lambda_{A}^{1} \\ p_{1} \cdot \frac{\partial \lambda_{A}^{2}}{\partial p_{1}} / \lambda_{A}^{2} & p_{2} \cdot \frac{\partial \lambda_{A}^{2}}{\partial p_{2}} / \lambda_{A}^{2} & \ldots & p_{n u} \cdot \frac{\partial \lambda_{A}^{2}}{\partial p_{n u}} / \lambda_{A}^{2} \\ \ldots & \cdots & \ldots & \cdots \\ p_{1} \cdot \frac{\partial \lambda_{A}^{m}}{\partial p_{1}} / \lambda_{A}^{m} & p_{2} \cdot \frac{\partial \lambda_{A}^{m}}{\partial p_{2}} / \lambda_{A}^{m} & \ldots & p_{n u} \cdot \frac{\partial \lambda_{A}^{m}}{\partial p_{n u}} / \lambda_{A}^{m}\end{array}\right]\left\{\begin{array}{c}u_{1} \\ u_{2} \\ \cdot \\ u_{n u}\end{array}\right\}$
$=\left\{\begin{array}{c}\left(\lambda_{X}^{1}-\lambda_{A}^{1}\right) / \lambda_{A}^{1} \\ \left(\lambda_{X}^{2}-\lambda_{A}^{2}\right) / \lambda_{A}^{2} \\ \cdot \\ \left(\lambda_{X}^{m}-\lambda_{A}^{m}\right) / \lambda_{A}^{m}\end{array}\right\}$

The above equation can be represented in a compact form as:

$[S]_{m \times n u}\{u\}_{n u \times 1}=\{\Delta e\}_{n u \times 1}$

where $\mathrm{S}$ is the sensitivity of eigenvalues with respect to the updating parameters and $\{\Delta e\}$ is a vector of difference between experimental and analytical eigenvalues. The above matrix equation is solved 
for $\{u\}$ using the routine for finding the pseudoinverse of a matrix available in MATLAB. The pseudo-inverse, calculated by the routine using singular-value decomposition of a matrix, is related to the least-squares problem, as the value of $\{u\}$ that minimizes $\|[\mathrm{S}]\{\mathrm{u}\}-\{\Delta \mathrm{e}\}\|^{2}$ can be given by $\{u\}=[S]^{+}\{\Delta e\}$. The superscript ' + ' denotes pseudo-inverse. The $\{u\}$ so found is used to update the vector of physical variables $\{p\}$, stiffness, and then the updated version of the analytical finite element model is built using the new values of stiffnesses. The process is repeated in an iterative way until convergence is achieved. To estimate the damping ratio from the frequency domain, the halfpower bandwidth method is used in the present study.

\section{Experimental setup}

The initial torque requirement for air-foil bearings is very high. To overcome this problem, an experimental setup is designed which uses a single air-foil bearing instead of standard two air-foil bearings. In this section, the designing of the experimental setup is given in detail. The design of the experimental setup includes section of the motor, analysis of the rotor, design of bearing supports and the design of the support.

\subsection{Selection of the motor}

The torque required to rotate the air-foil bearing supported rotor is greatest when the rotor is in contact with the stator before there is sufficient speed to generate a fluid film separating the two surfaces. To initiate rotation sufficient torque must be applied to the rotor to overcome the sliding frictional forces in the air-foil bearings, the rotor inertia and the required rotational acceleration. Once sliding begins the torque requirement to sustain rotation drops since the kinematic coefficient of friction is typically less than the static coefficient of friction. Upon development of the fluid film and rotor lift-off the torque requirement for rotation will further decline. Due to the initial high torque requirement, researchers have used a high speed and torque turbines (Kim and Park 2009; Isomura et al. 2005; Belforte et al. 2006) or a separate high torque starting motor (San Andrés and Kim 2008) and high speed rotor. Both types of experimental setups are expensive. In order to reduce the cost of experimental setup, the experimental setup is designed such that a single air-foil bearing can be used instead of two bearings. The torque and power characteristics of the selected motor are given in Fig. 4. It can be noticed from Fig. 4a that the initial torque of the selected motor is $0.6 \mathrm{Nm}$ and it can run up to a speed of $60,000 \mathrm{rpm}$. It is very important to know that the first natural frequency of the shaft is far above the operational speed of the motor shaft. The modal analysis of the motor was also carried out to find out the natural frequency of the motor shaft. The motor shaft was excited by an impact hammer and the response was measured using an accelerometer. A response plot of the motor is shown in the Fig. 5. It can be observed from Fig. 5 that the first bending natural frequency of the motor shaft is above $3000 \mathrm{~Hz}$ which is far above the operation speed of 1000 rps. The axial and radial stiffness of the whole motor system was identified in light of the experimental results, which comes out to be $2 \times 10^{10}$ and $1.6 \times 10^{11} \mathrm{~N} / \mathrm{m}$, respectively.

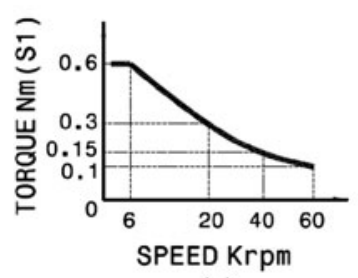

(a)

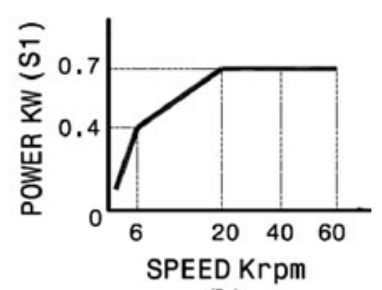

(b)
Fig. 4 a Torque and b Power characteristics of the selected motor

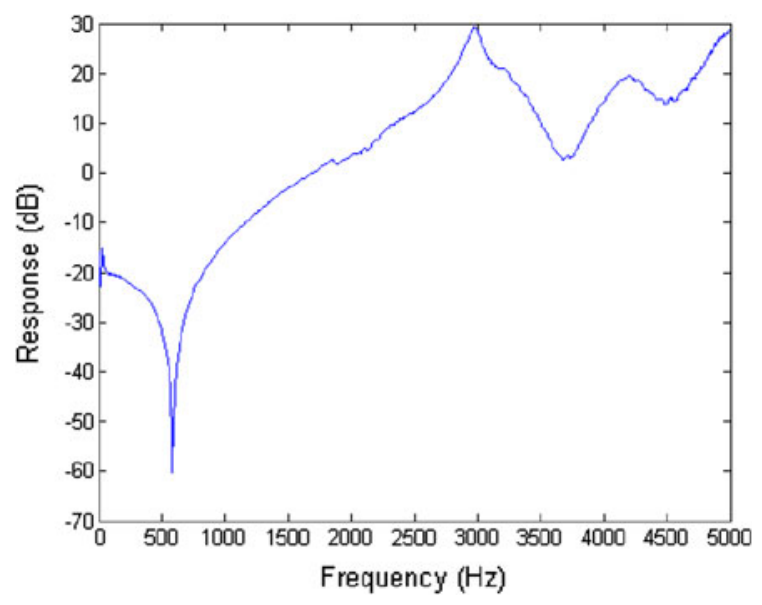

Fig. 5 Response of motor shaft 
Fig. 6 Details of the rotor and measurement points
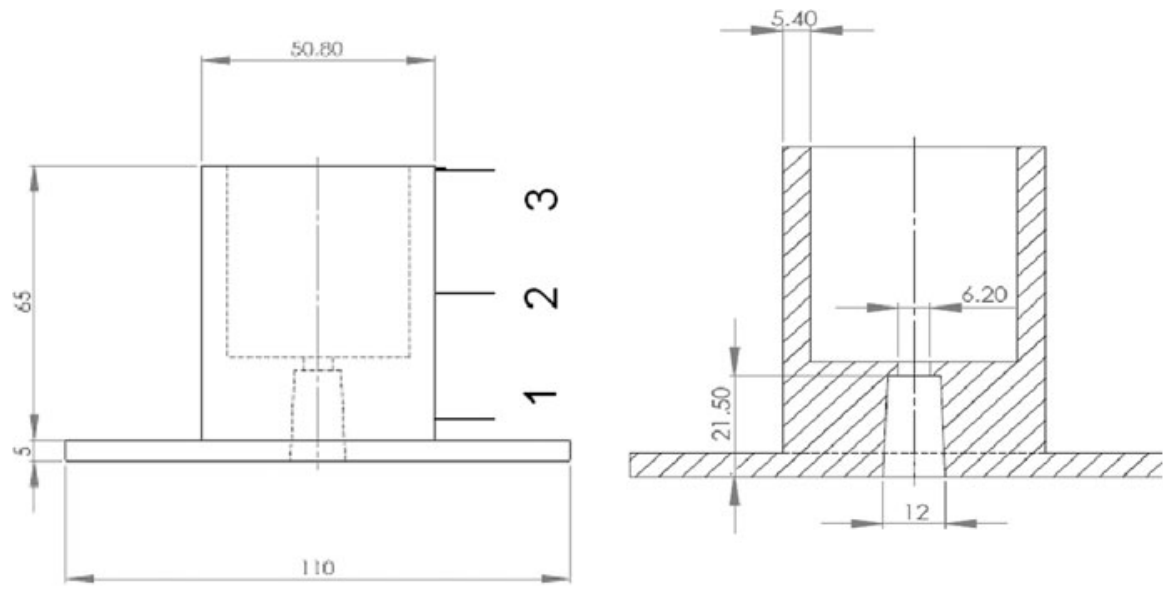

Table 1 Natural frequencies of the rotor using FE model

\begin{tabular}{ll}
\hline Mode number & Natural frequency $(\mathrm{Hz})$ \\
\hline 1 & 0 \\
2 & 0 \\
3 & 0 \\
4 & $5.0 \mathrm{e}-003$ \\
5 & $6.8 \mathrm{e}-003$ \\
6 & $1.1 \mathrm{e}-002$ \\
7 & 4360.9 \\
8 & 4386.8 \\
9 & 4528.1 \\
10 & 4714.7 \\
\hline
\end{tabular}

\subsection{Rotor}

The rotor was designed to have its first natural frequencies above the operating speed of the system. The details of the rotor are shown in Fig. 6. It can be observed from Fig. 6 that the rotor is a stepped rotor and is hollow. The finite element of the rotor was built in MATLAB using beam elements. The lowest natural frequencies of the free-free rotor are given in Table 1. It can be noticed from the Table 1 that the first natural frequency is far above the proposed operating speed of the rotor. The experimental modal analysis of the free-free rotor was carried out to validate the FE model results of the rotor. The freefree condition is achieved by hanging the rotor in flexible strings. The modal test is performed by exciting the rotor with an impact hammer and the response is measured at one location using an accelerometer. The measurements on the rotor were carried out at three different locations spaced equally along the length of the shaft as shown in Fig. 6. The first natural frequency of the rotor is $4200 \mathrm{~Hz}$, which is very close to the natural frequency predicted by $\mathrm{FE}$ model.

\subsection{Motor support}

The motor support has been designed and manufactured. The solid model of the motor support is given in Fig. 7. It can be observed from Fig. 7 that the motor support holds the motor from the back and it is clamped to the base-plate of the foundation at the bottom. The modal analysis of the motor support was carried out in isolation to find out the stiffnesses in horizontal and vertical direction. The data is acquired by exciting the motor support by impact hammer and measuring the response using accelerometers. The stiffnesses of the motor support are identified in horizontal and vertical direction using experimental data. The identified horizontal and vertical stiffnesses are $1.087 \times 10^{7}$ and $1.4 \times 10^{7} \mathrm{~N} / \mathrm{m}$. The mass of the back plate, of the motor support is used for identification of stiffnesses. The mass of the back plate is approximately $2.5 \mathrm{~kg}$.

\subsection{Radial bearing support}

Figure 8 shows the view of the flexible support unit, the bearing and housing being supported. The bearing is housed within a square aluminum block of size $150 \times 150 \mathrm{~mm}$ and thickness $25.4 \mathrm{~mm}$. The outer frame is rigidly fixed to the base plate by means of a bolt passing through the central slot in the base plate. 
Fig. 7 a 3-D model and b side view of the motorsupport

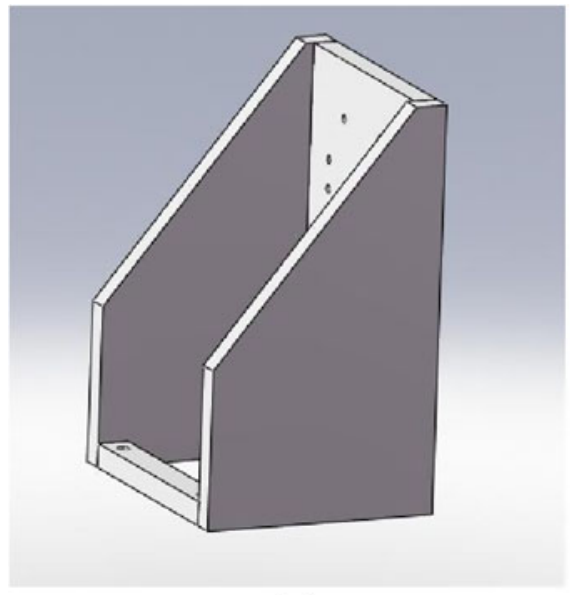

(a)

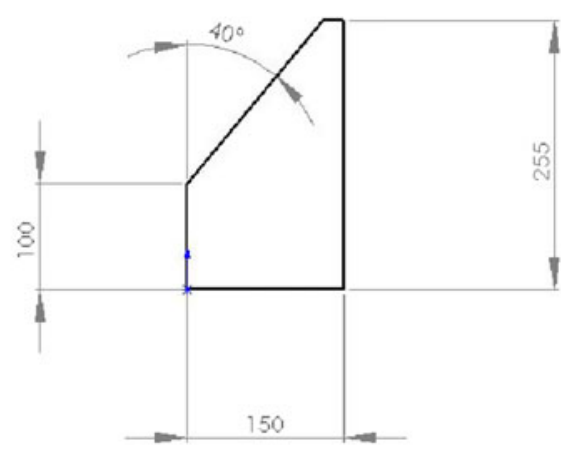

(b)

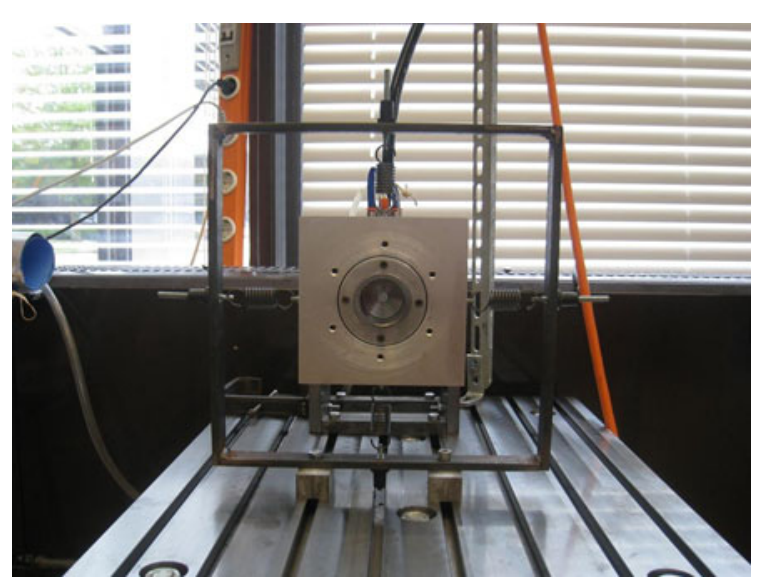

Fig. 8 Pictorial view of radial bearing support

In order to reduce the type of dynamic behavior present in a real machine mounted on flexible foundations, it is necessary for the connection between the bearing and the outer frame (which is analogous to the physical earth of the foundations in a real machine) to be flexible. The flexibility is introduced by use of steel extension springs. The springs are connected to the outer frame by M4 bolts. These bolts are long enough to pass through holes in the frame using M4 neoprene anti-vibration fasteners. The most straightforward way to determine the stiffness of the bearing support system is to perform an impact test on the support unit, without rotor in place and whilst rigidly bolted to the base plate. The measured natural frequencies are then used in conjunction with the measured mass to calculate the support stiffness in the direction of being measured.

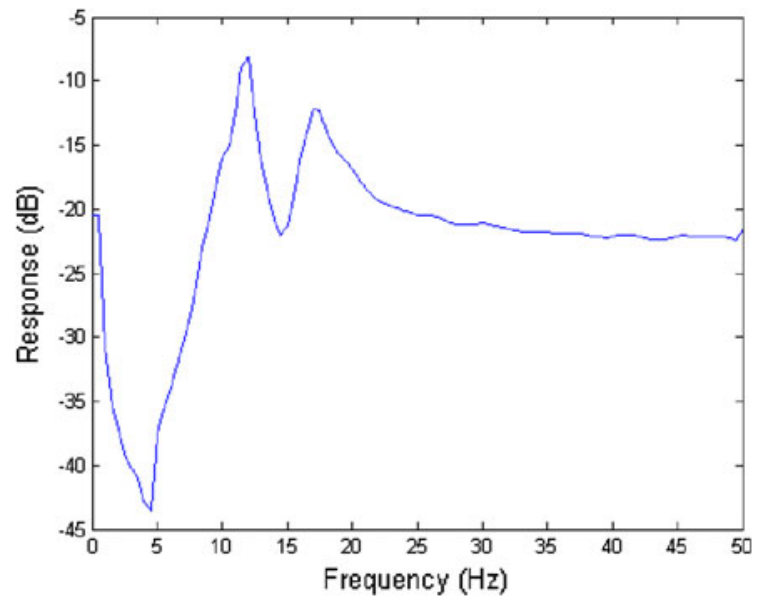

Fig. 9 Response of the radial bearing

The test is performed in both horizontal and vertical direction. The response in horizontal direction is given in Fig. 9. It can be observed that the stiffness of the springs is very low, so they provide flexibility to the system. The whole bearing/support arrangement is designed to allow adjustment of the distance between bearing housing and the outer frame. This was important for alignment of the rotor, as well as for applying pre-tension to the springs.

\section{Radial bearing experimental setup}

In this section, the experimental setup for radial bearing identification is presented. All the components, which are discussed in the previous sections, 


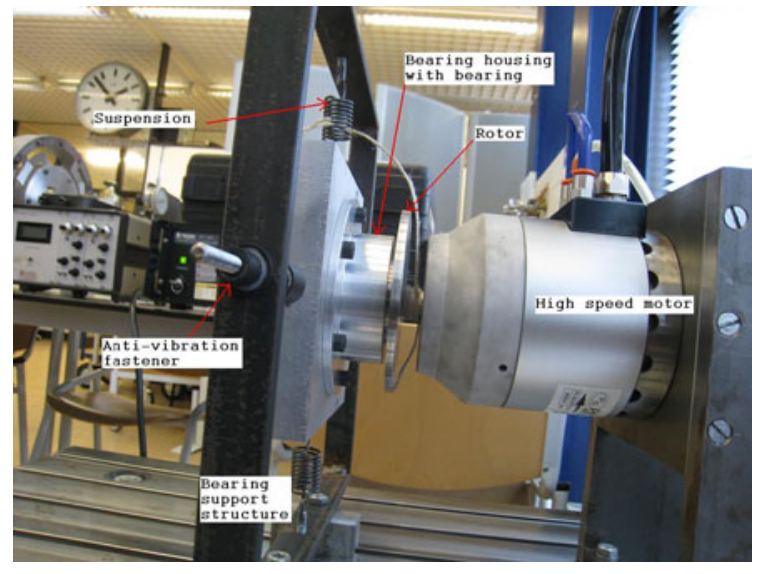

Fig. 10 Radial bearing setup

are assembled to form the complete experimental setup. The radial bearing experimental setup is shown in the Fig. 10. It can be noticed from Fig. 10 that the high speed motor is clamped to the support from behind, which in turn is bolted to the base plate of the foundation. The radial setup consists of a bearing support structure, in which the radial bearing housing is suspended. This suspension allows for movement in the radial direction only. The radial bearing is placed in between the bearing housing and the rotor, which in turn is attached to a high speed motor drive. The rotor is clamped to the motor on one end and on the other side the rotor disk is in contact with the radial bearing. The radial bearing is pressed between the rotor disc and the radial bearing support as shown in Fig. 11. In case of the air-foil bearing, the initial torque requirement is very large. To determine the natural frequencies and corresponding amplitudes of the radial bearing test setup under different running speeds up to maximum speed of $60,000 \mathrm{rpm}$ with increments of 5,000 rpm, to be used as input for determining the radial bearing stiffness and damping characteristics.

\subsection{Test equipment}

- Exciter (static measurements only): Bruel \& Kjaer impact hammer type 8202 with force transducer type 8200

- Vibration pick-up: Bruel \& Kjaer accelerometer type 4393

- Amplifier: Bruel \& Kjaer Nexus Conditioning Amplifier type 2690

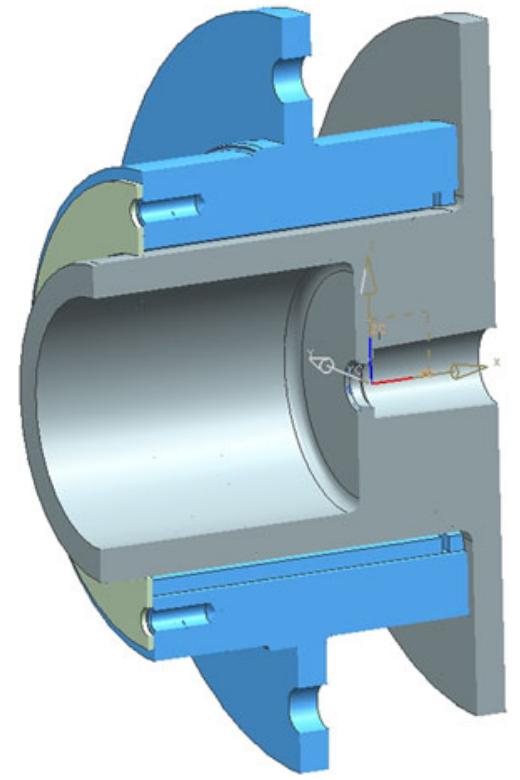

Fig. 11 Contact between rotor and bearing support for radial bearing

- AD converter: DSP SigLab model 20-42

- FFT software: MATLAB vna module

\subsection{Measurements and post-processing}

Measurements are carried out by exciting and measuring the structure in one of the two highlighted locations. This will take place at RPM ranging from 0 to 60000 in 5000 RPM increments (13 measurements). The rotor bearing system is excited by modal hammer and the response is measured by an accelerometer. Since the natural frequencies of the support structure and motor bearings are determined in earlier measurements, the natural frequency of the bearing can be isolated. In this manner, the stiffnesses $\mathrm{k}_{\mathrm{hh}}, \mathrm{k}_{\mathrm{vv}}$ and $\mathrm{k}_{\mathrm{hv}}$ and $\mathrm{k}_{\mathrm{hv}}$ are determined, similarly the damping properties are identified. The subscript $\mathrm{h}$ and $\mathrm{v}$ denotes horizontal and vertical directions. Specified amount of pre-stress is applied on the radial bearing.

\subsection{Sub-structuring}

The sub-structuring technique has been employed for identification of the bearing characteristics. Figure 12 shows the partially assembled experimental setup consisting of motor support, motor and rotor. Addition of components adds natural frequencies to the 


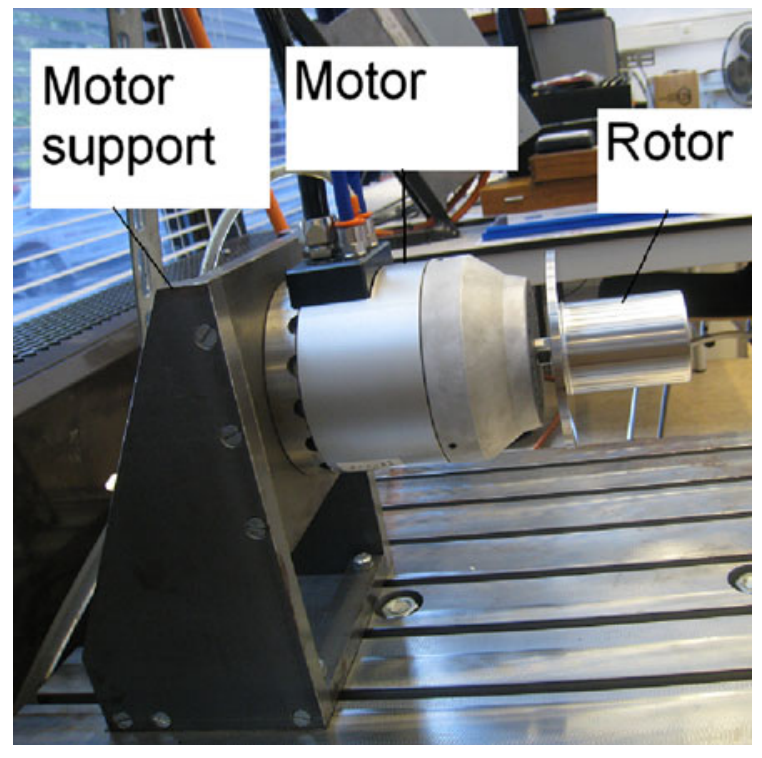

Fig. 12 Sub-structure consisting of motor support, motor and rotor

Table 2 Comparison of natural frequencies of sub-structure and complete structure

\begin{tabular}{lll}
\hline Mode number & $\begin{array}{l}\text { Motor }+ \text { support }+ \\
\text { rotor }(\mathrm{Hz})\end{array}$ & $\begin{array}{l}\text { Complete } \\
\text { system }(\mathrm{Hz})\end{array}$ \\
\hline 1 & 283 & 12.1 \\
2 & 332 & 17.2 \\
3 & & 47.5 \\
4 & & 124 \\
5 & & 282.8 \\
\hline
\end{tabular}

system. This can be illustrated by taking the example of a sub-structure of the experimental setup and complete radial bearing test rig. Because of the addition of the support and the radial bearing, there is an addition of the natural frequencies in the system as given in the Table 2. It can be noticed from Table 2 that because of the introduction of the radial bearing, two natural frequencies at 47.5 and $124 \mathrm{~Hz}$ are introduced. These frequencies are because of the stiffness of the radial bearings. From this conclusion for each speed, the experimental data is acquired and is then analyzed to find the natural frequencies and damping ratios which then subsequently can be used for identification of stiffness and damping of the radial bearing.

The finite element model of the rotor system is developed using 2D-beam elements. This beam element has 8 degrees of freedom; each node has 4 degrees of freedom. Two translational and two rotational degrees of freedom (Jalan and Mohanty 2009). The stiffness properties of each component identified in the previous section are then included in the finite element model of the rotor to develop complete model of the system. Initially, an arbitrary value of the bearing stiffness is assigned to the rotorsupport-bearing system. The modal analysis of the finite element model is carried out to find its dynamic characteristics. The predicted dynamic characteristics of the finite element model are compared with the experimental data obtained while applying a prestress of specified amount.

\section{Results}

The experimental tests are conducted to acquire experimental data at increments of $5,000 \mathrm{rpm}$ up to the maximum speed of $60,000 \mathrm{rpm}$ as given in the test plan. The experimental data is then analyzed to obtain natural frequencies and damping ratios. The experimental natural frequencies and damping ratios are then used to identify the stiffness and damping of the radial bearing. The stiffness and damping of radial bearing is identified using the identification algorithm developed in Sect. 2. The finite element model of the rotor bearing system and identification algorithm is developed in MATLAB. The identified stiffness and damping values are given in Figs. 13, 14,15 and 16.

It can be observed from Figs. 13 and 14 that the identified stiffness values in horizontal and vertical direction are similar to each other and are in the region of $3 \times 10^{5} \mathrm{Nm}$. In these plots values of the stiffness at static condition is not plotted as the value of stiffnesses are very high at $1.4 \times 10^{6} \mathrm{Nm}$. It can also be observed from Figs. 13 and 14 that there is an increase of stiffness at high speed. This phenomenon in literature is known as hardening effect (San Andrés and Kim 2009) of the air film. Hardening effects means the at very high speed the trapped air in the bearing becomes very stiff and it results in the increase of stiffness of the bearing but the magnitudes of stiffnesses in horizontal and vertical directions are different. There is increase in stiffness of the bearing at high speed for the vertical bearing it is $6.2 \%$ and horizontal bearing $15.3 \%$. The identified damping at various speeds remains more or 


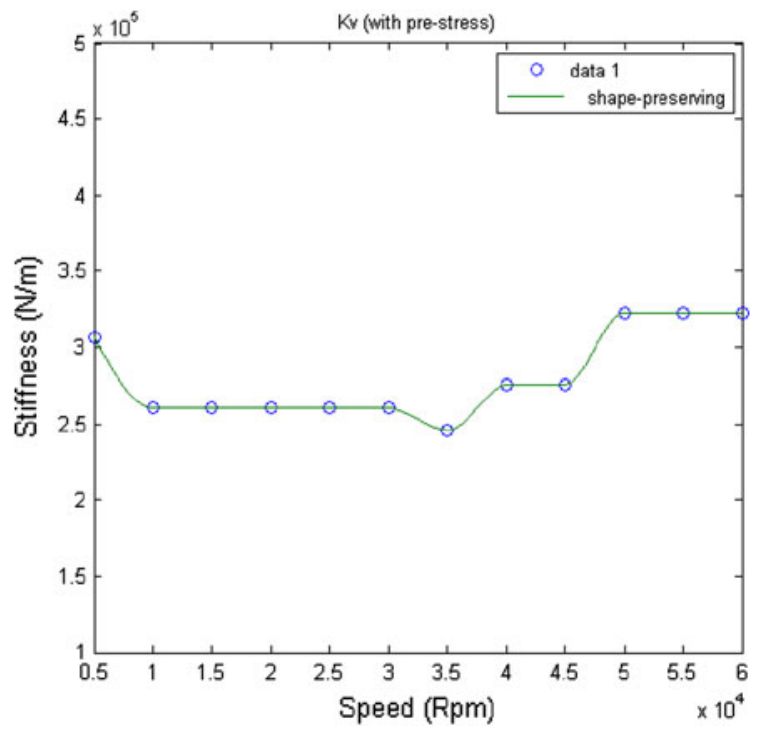

Fig. 13 Identified vertical direction stiffness at various speed for radial bearing

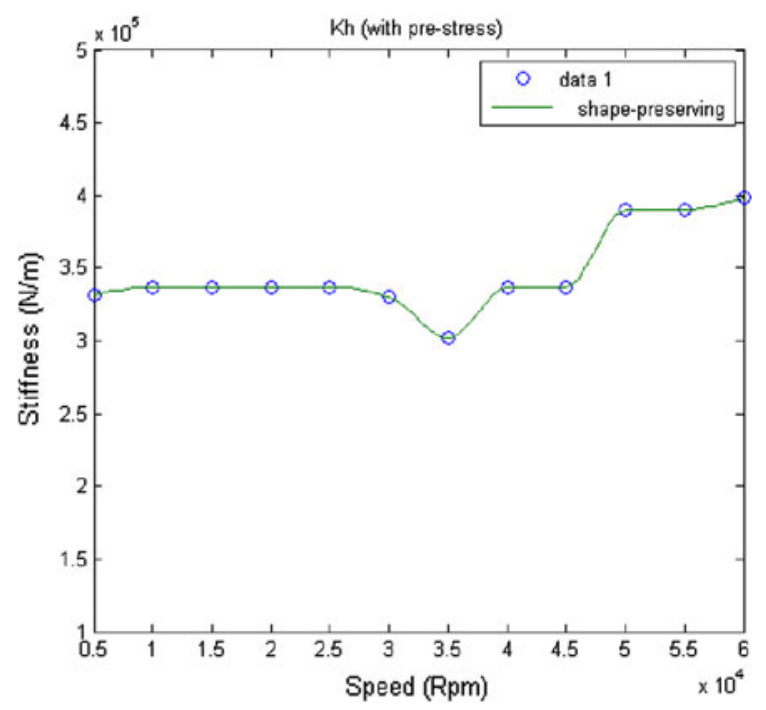

Fig. 14 Identified horizontal direction stiffness at various speed for radial bearing

less same. Small change is observed at very high speeds as shown in Figs. 15 and 16.

\subsection{Torque loss}

One of the factors that determine the efficiency of a system with AFBs is the torque loss which occurs in the air layer between the shaft and the top foils. For high speeds the shearing of the air film will likely

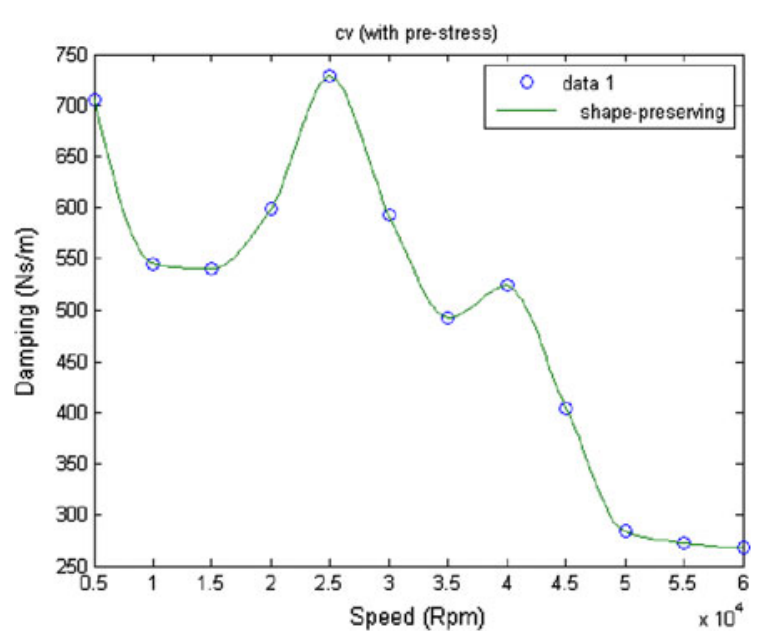

Fig. 15 Identified vertical direction damping at various speed for radial bearing

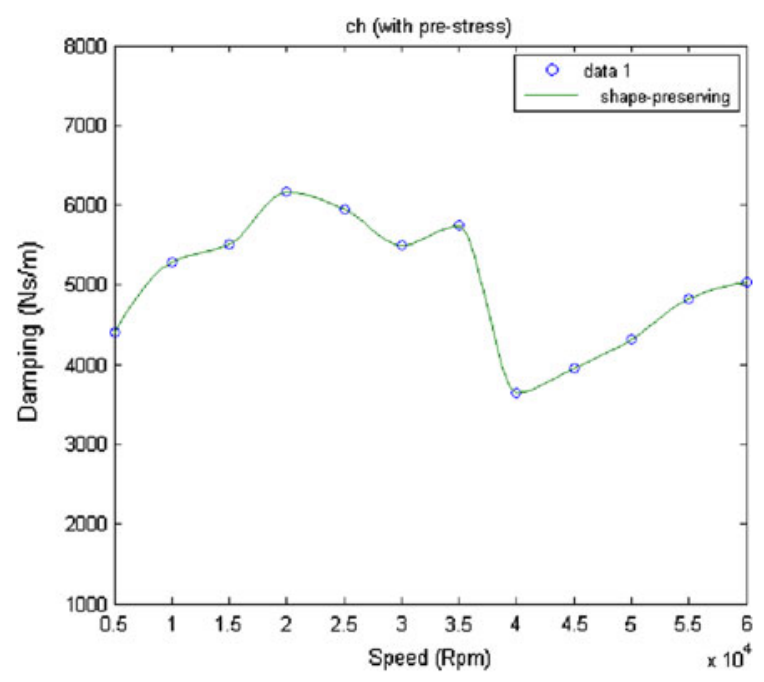

Fig. 16 Identified horizontal damping at various speed for radial bearing

cause a torque loss in some way proportional to the shaft speed. While it is possible to measure the electro-spindle's output torque in different steadystate running conditions, this will not provide a good estimation of the torque loss caused by the AFB alone. This is because the roller bearings in the motor, along with electrical losses in the coils, also increase the required torque. It is because of this that a mechanical way of torque measurement is devised, using the existing experimental setup. The torque loss arrangement is shown in Fig. 17. For different shaft speeds, the torque is measured by read out the value 
of the strain gauge, and by multiplying by $d$ (distance) convert to $\mathrm{Nm}$ of torque. The results are shown in blue in Fig. 18. It appears that a quadratic relation exists between torque loss and shaft speed. An estimated quadratic curve (generated using the least-squares method) is also shown in green. The curve's formula is

$$
\begin{aligned}
T= & 6.2672 \times 10^{-2} \cdot R^{2}+2.1999 \times 10^{-7} \cdot R \\
& +0.0168
\end{aligned}
$$

where $\mathrm{T}$ is the torque loss and $\mathrm{R}$ the shaft speed in rpm.

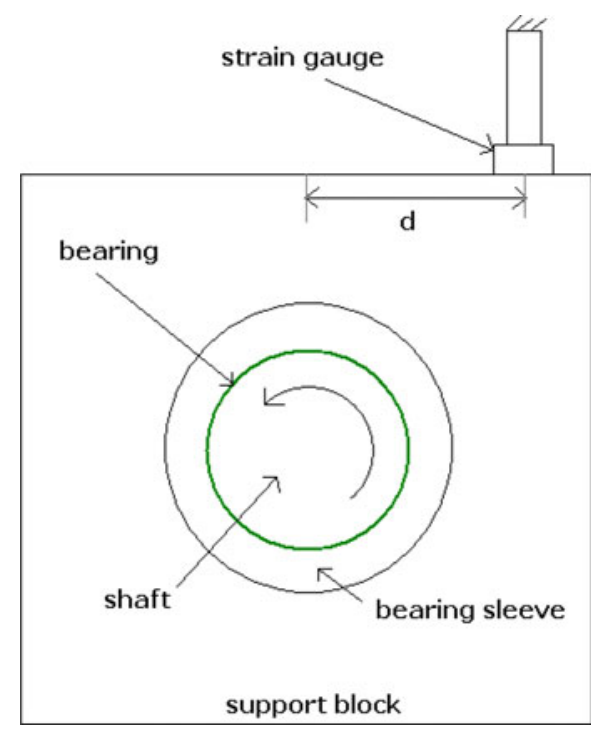

Fig. 17 Arrangement for measuring torque for radial bearing

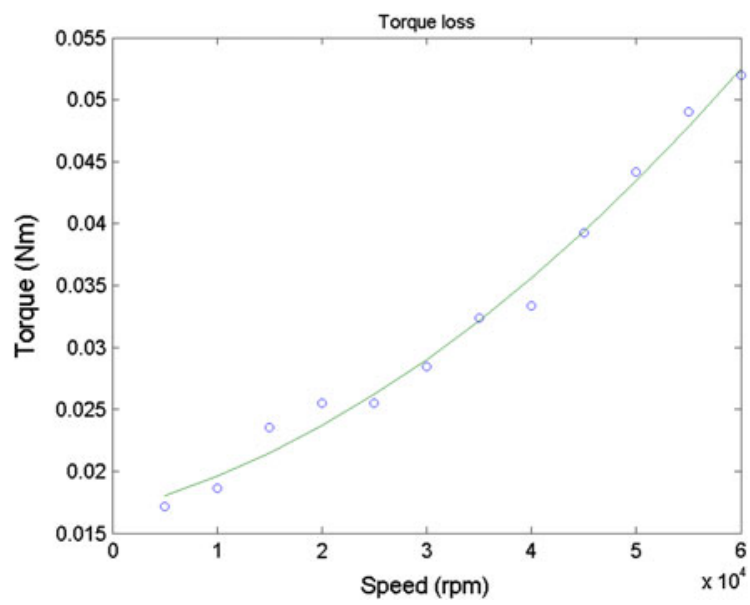

Fig. 18 Torque loss at various speeds

\subsection{Force-deflection diagram}

The force-deflection (F-D) characteristics of the radial bearing are also carried out by applying a force in one direction and by measuring the resulting deflection in the other direction in static condition. F-D plots in horizontal and vertical directions are shown in Figs. 19 and 20. It can be observed from Figs. 19 and 20 that the relationship between force and deflection is linear. From the force-deflection plots values for the stiffness are calculated. The identified values of the stiffness in vertical and horizontal directions are $1.21 \times 10^{6}$ and $1.22 \times 10^{6}$ $\mathrm{N} / \mathrm{m}$ respectively. The identified stiffness values are very close to the values identified using the developed algorithm. In the developed algorithm, the stiffness values are identified using the vibration data and is being used for identifying stiffnesses at various speeds. From the force-deflection study, it can be concluded that the developed algorithm works well for identifying the structural characteristics of the air-foil bearing.

\section{Conclusions}

The main focus of this work is to identify the structural characteristics of radial air-foil bearings. A sub-structuring technique is used in the present work. The structural characteristics of each component are identified in isolation and then identified structural characteristics of each component are used

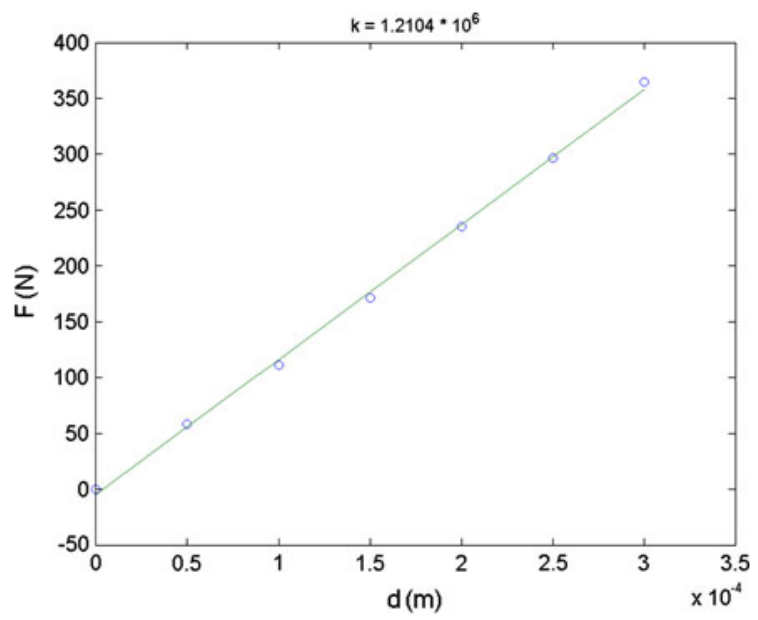

Fig. 19 Force-deflection plot in vertical direction 


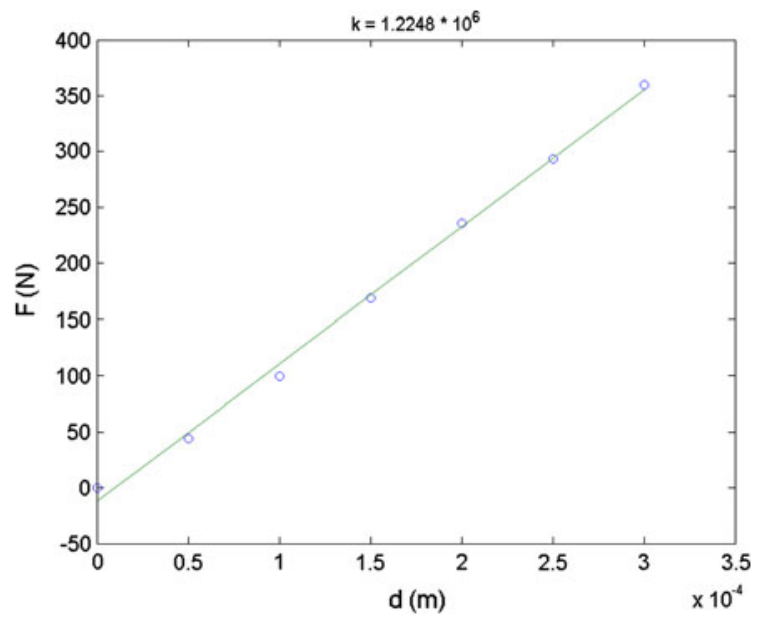

Fig. 20 Force-deflection plot in horizontal direction

in developing the finite element model of the rotorbearing-support system. A new identification algorithm for air-foil bearing is developed. It is based on inverse eigensensitivity method and it uses eigendata for identification of the structural characteristics of the bearings. Arrangements have been designed to apply pre-stress. The developed algorithm is working well. From the identification results, it can be concluded that at very high speeds, the hardening effects are observed. The stiffnesses calculated from the force-deflection curves are comparable with the identified stiffness using the developed algorithm.

Acknowledgements The work presented in this paper was supported by research grant from NIVR and Aeronamic aircraft subsystems.

Open Access This article is distributed under the terms of the Creative Commons Attribution Noncommercial License which permits any noncommercial use, distribution, and reproduction in any medium, provided the original author(s) and source are credited.

\section{References}

Arora, V., Singh, S.P., Kundra, T.K.: Damped model updating using complex updating parameters. J. Sound Vib. 320, 438-451 (2009a)

Arora, V., Singh, S.P., Kundra, T.K.: Finite element model updating with damping identification. J. Sound Vib. 324, 1111-1123 (2009b)

Belforte, G., Raparelli, T., Viktorov, V., Trivella, A., Colombo, F.: An experimental studyof high-speed rotor supported by air bearings: test rig and first experimental results. Tribol. Int. 39, 839-845 (2006)

DellaCorte, C., Valco, M.: Load capacity estimation of foil air Journal bearing for oil-Free turbomachinery applications. STLE Tribol. Trans. 43, 795-801 (2000)

Chen, J.H., Lee, A.C.: Estimation of linearized dynamic characteristics of bearing using synchronous response. Int. J. Mech. Sci. 37, 197-219 (1995)

Edwards, S., Lee, A.W., Friswell, M.I.: Experimental identification of excitation and support parameters of flexible rotor-bearings-foundation system from a single run-down. J. Sound Vib. 232, 963-992 (2002)

Fox, R.L., Kapoor, M.P.: Rates of changes of eigenvalues and eigenvectors. AIAA J. 6, 2426-2429 (1968)

Heshmat, H., Ku, C.P.: Structural damping of self-acting compliant foil journal bearings. ASME J. Tribol. 116, 76-82 (1994)

Kim, D., Park, S.: Hydrostatic air-foil bearings: analytical and experimental investigation. Tribol. Int. 42, 413-425 (2009)

Isomura, K., Tanaka, S., Togo, S., Esashi, M.: Development of high-speed micro-gas bearings for three dimensional micro-turbo machines. J. Micromech. Microeng. 15, 222-227 (2005)

Jalan, A.K., Mohanty, A.R.: Modal based fault diagnosis of a rotor-bearing system for misalignment and unbalance under steady-state condition. J. Sound Vib. 327, 604-622 (2009)

Jiang, P.L., Yu, L.: Identification of the oil-film dynamic coefficients in the rotor-bearing system with a hydrodynamic thrust bearing. J. Sound Vib. 236, 733-740 (2000)

Kim, Y.H., Yang, B.S., Tan, A.C.C.: Bearing parameter identification of rotor-bearing system using cluster-based hybrid evolutionary algorithm. Struct. Multi. Opt. 33, 493-506 (2007)

$\mathrm{Ku}, \mathrm{C} . \mathrm{P} .:$ An experimental and theoretical study of the dynamic structural stiffness in compliant foil journal bearings. ASME 14th biennial conference on Mechanical Vibration and Noise, Albuquerque 63, 83-88 (1993)

$\mathrm{Ku}$, C.P., Heshmat, H.: Complaint foil bearing structural stiffness analysis part II: experimental investigation. ASME J. Tribol. 115, 364-369 (1993)

$\mathrm{Ku}$, C.P., Heshmat, H.: Structural stiffness and coulomb damping in compliant foil journal bearing: theoretical considerations. STLE Tribol. Trans. 37, 525-533 (1994a)

$\mathrm{Ku}$, C.P., Heshmat, H.: Structural stiffness and coulomb damping in compliant foil journal bearing: parametric studies. STLE Tribol. Trans. 37, 455-462 (1994b)

Lee, C.W., Hong S.W.: Identification of bearing dynamic coefficients by unbalance response measurements. In: Proceedings Inst. Mech. Eng. Conference, pp. 93-101 (1998)

Modak, S.V., Kundra, T.K., Nakra, B.C.: Comparative study of model updating methods using simulated experimental data. Comput. Struct. 80, 437-447 (2000)

Rubio, D., San Andrés, L.: Bump-type foil bearing structural stiffness: experimentation and predictions. J. Eng. Gas Turbine Power. 128, 653-660 (2006)

Salehi, M., Heshmat, H., Walton, J.: On the frictional damping characterization of compliant bump foils. ASME Trans. 125, 804-813 (2003) 
San Andrés, L., Kim, T.H.: Forced nonlinear response of gas foil bearing supported rotors. Tribol. Int. 704, 413-715 (2008)

San Andrés, L., Kim, T.H.: Analysis of gas foil bearings integrating FE top foil models. Tribol. Int. 42, 111-120 (2009)
Tiwari, R., Lee, A.W., Friswell, M.I.: Identification of speeddependent bearing parameters. J. Sound Vib. 254, 967-986 (2002) 